\title{
PROCESOS CONTEMPORÁNEOS DE ACTIVACIÓN PATRIMONIAL: TENSIONES, DISPUTAS Y CONSENSOS ENTRE LAS COMUNIDADES. EL CASO DE BELLAVISTA EN TOMÉ, CHILE*
}

\section{CONTEMPORARY PATRIMONIAL ACTIVATION PROCESSES: TENSIONS, DISPUTES AND CONSENSUS AMONG COMMUNITIES. THE CASE OF BELLAVISTA IN TOMÉ, CHILE}

\author{
RODRIGO HERRERA OJEDA**, MARÍA ISABEL LÓPEZ MEZA***, \\ MARÍA FERNANDA MORALES ORTIZ ${ }^{\star * * *}$
}

ReSUMEN: No sin conflicto, los procesos contemporáneos de patrimonialización en Chile muestran un desplazamiento desde la perspectiva tradicional -funcional al discurso de Estado nación y del mercado- hacia planteamientos más complejos e inclusivos. Esta tendencia exige de los agentes involucrados importantes capacidades de negociación, a la vez que voluntad política para transitar hacia una co-construcción del patrimonio. A partir del análisis de discursos de entrevistas en profundidad, trianguladas con datos secundarios, analizamos el proceso de declaratoria de la Fábrica Bellavista Oveja Tomé, en la ciudad de Tomé, como Monumento Histórico; un edificio de propiedad privada e ícono para la comunidad local. Los resultados del análisis del material indican que las alteridades que alcanzan sus objetivos son aquellas que han logrado desarrollar un activismo complejo, que utiliza tanto formas institucionales como 'no institucionales' de acción y, sobre todo, que regula los niveles de presión que impulsa, de manera de no quebrar la mesa de negociaciones, pero que a la vez logra alterar las perspectivas hegemónicas 'oficializando' el patrimonio 'no oficial'.

Palabras Clave: Construcción social del patrimonio, agentes patrimoniales, activación patrimonial, Fábrica Bellavista Oveja Tomé.

AвSTRACT: Not without struggle, contemporary heritagization processes in Chile show a shift from traditional perspectives - functional to the nation state discourse and the

* Artículo elaborado a partir del proyecto de investigación FONDECYT Regular N¹190992, "Escenarios probables de preservación o pérdida del patrimonio construido en proceso de conflicto social; el caso del patrimonio textil de Tomé". Investigadora responsable: María Isabel López.

** Doctor en Antropología Social y Cultural, Director de Vinculación Social de la Vicerrectoría de Relaciones Institucionales y Vinculación con el Medio (VRIM), Universidad de Concepción, Concepción, Chile. Correo electrónico: rherrerao@udec.cl. Orcid: https://orcid.org/0000-0002-8750-8936

*** Doctora en Desarrollo Urbano Sostenible, Universidad Politécnica de Madrid, académica Depto. Planificación y Diseño Urbano y Directora del Magíster en Patrimonio Arquitectónico y Urbano, Facultad de Arquitectura, Construcción y Diseño, Universidad del Bío-Bío, Concepción, Chile. Correo electrónico: mlopez@ubiobio.cl. Orcid: https://orcid.org/0000-0002-0942-9722

*** Magíster en Patrimonio Arquitectónico y Urbano. Programa de Interculturalidad (UCO 1995), Universidad de Concepción, Concepción, Chile. Correo electrónico: mariafmorales@gmail. com. Orcid: https://orcid.org/0000-0002-3859-1729 
private market - to more complex and inclusive processes. This new trend is demanding important negotiation capacities as well as the political will of the different agents at stake, in order to achieve the co-construction of heritage. Through discourse analysis and in-depth interviews, double crossed with secondary data, we analyzed the designation of Bellavista Oveja Tomés industry as a historical monument; a privately-owned building and a symbolic icon for the local community. The results indicate that heritage groups achieving their agendas are those developing complex forms of activism; including both institutional and non-institutional actions. And also, those who calibrate the level of social pressure just beneath the threshold of breaking the bargaining arena, but high enough in order to overthrow hegemonic notions of heritage. In this way heritage activists are indeed making 'official' the 'non-official'.

KeYwords: Social construction of heritage, heritage agents, patrimonial activity, Bellavista Oveja Tomé Cloth Factory.

Recibido: 08.07.2020. Aceptado:16.04.2021.

\section{INTRODUCCIÓN}

$\mathrm{E}$ L 7 DE NOviembre de 2016, la Ministra de Educación de la época ratifica la declaratoria de la Fábrica Bellavista Oveja Tomé (en adelante FBOT), en su calidad de Monumento Histórico. Aquel evento vino a señalar un hito en la historia del recinto, también de las dinámicas de activación patrimonial en nuestro país. Factores como el tiempo que involucró el proceso, las relaciones entre los distintos agentes entre sí y las inevitables tensiones derivadas de estas relaciones, muestran interesantes datos para lograr entender estas dinámicas contemporáneas de activación patrimonial en Chile.

Para comprender mejor este proceso, el presente trabajo exploró los discursos de los distintos agentes que se conformaron e influyeron en la declaratoria de FBOT, para reconstruir desde allí los diversos puntos de partida, realineamientos, intereses y agendas, que permiten apreciar la manera en que -desde el marco normativo y social chileno- las distintas colectividades abordaron el proceso de declaratoria patrimonial, así como las estrategias utilizadas para apoyarla, encauzarla o impedirla.

\section{LOS PROCESOS DE ACTIVACIÓN PATRIMONIAL Y SUS AGENTES}

La tendencia hacia una mayor 'democratización' del patrimonio a nivel global, expresada en la Convención para la Salvaguarda del Patrimonio Cultural Inmaterial de 2003 de la UNESCO (instrumento normativo que, 
no obstante, entró en vigor el 2006), ha visibilizado nuevos colectivos y otorgado protagonismo a "comunidades, grupos y en algunos casos individuos", consolidando un nuevo paradigma participativo en relación a la identificación, definición y diseño de la gestión del patrimonio (Quintero y Sánchez, 2017, p. 6).

Si bien respecto a esta tendencia no caben muchas discrepancias, un efecto de ella son las diferencias generadas en la comprensión de qué se entiende por patrimonio. Para unos actúa como ámbito que le da sentido a la memoria, transformándose en factor de cohesión grupal, permitiendo el reforzamiento de lazos y otorgando sentido de continuidad a la comunidad (Hernández y Moyano, 2007). La participación, en este sentido, es fundamental como gatillador de dinámicas que permiten a una comunidad centrarse en sí misma, pensarse y proyectarse. Otros, en cambio, no dejan de ver en estos discursos un andamiaje narrativo que oculta asimetrías y sometimientos eurocéntricos, en directa complicidad con procesos de espectacularización y beneficio comercial (Coronil, 2000; Santamarina, 2013). Desde esta perspectiva, el paradigma participativo constituiría más bien un intento de repolitización al servicio de una agenda neoliberal; una suerte de tecnología de autoayuda que produce y reproduce una idea de régimen patrimonial dependiente de los principios del neoliberalismo y sus ilusiones de igualdad (Jiménez-Esquinas y Sánchez, 2016). Por efecto de ello, se conformaría como dispositivo de poder e instrumento de intervención, disciplinamiento y exclusión social al servicio de la construcción de una ciudadanía tributaria de cierto tipo de gobernabilidad (Salgado, 2008).

Lo interesante es que ambas perspectivas no son excluyentes. Al menos, las dos reconocen el paradigma de la construcción social del patrimonio, el que apoyado por procesos de participación, logra visibilizar tensiones y conflictos previamente atenuados por la preeminencia de la fórmula en la cual el diagnóstico, valoración y gestión patrimonial era una tarea exclusiva de 'expertos' e instituciones formales. Desde esta perspectiva, algunos ven emerger nuevos sujetos ya no solo satisfechos con ser público pasivo de procesos simbólicos que se consolidan a su alrededor, sino empoderados como agentes activos en la definición y gestión de su memoria e identidad colectiva (Guerrero, 2012). Estas consideraciones agregan al fenómeno de la construcción social del patrimonio una variable sociopolítica, al conjugar complejas elaboraciones simbólicas que atañen a la construcción y reafirmación de identidades colectivas (Maillard, 2012). De hecho, los propios procesos de activación patrimonial se observan como instancias que ya no pueden ser vistas como neutrales, sino más bien como campos de disputa 
entre actores con disímiles cuotas de poder (Harvey, 2010; Jiménez-Esquinas y Sánchez, 2016; Jiménez-Esquinas y Quintero, 2017).

De acuerdo a este enfoque, el énfasis se traslada desde una mirada centrada en un discurso patrimonial estático y unívoco, a un reconocimiento de las diversas agencias y tensiones que van orientando un proceso siempre dinámico de construcción social, cuya naturaleza disonante viene dada por negociaciones permanentes de significados colectivos entre agentes que buscan inducir dinámicas de resemantización y cambios de uso de elementos, sitios, prácticas e inmuebles, que forman parte del diario vivir.

Este devenir ha conducido al surgimiento de verdaderos movimientos cívicos que se proponen orientar y conducir estos procesos. Ariño (2010) los visualiza divididos en dos grandes grupos. Unos serían aquellos colectivos que reivindican su patrimonio a través de la celebración ritual, asociativa y carnavalesca. Realizan sus performances a partir de la sensación de pérdida, por lo que la puesta en escena se enfoca en salvar del olvido objetos, prácticas, usos y vestimentas. Esto porque, además de rememorar, se busca traer al presente representaciones de autenticidad de un mundo ya no visible, enfatizando con ello lo extra-ordinario. En otra vereda estarían los movimientos sociales reivindicativos que buscan la protección de bienes culturales frente a lo que es sentido como una agresión que acompaña los procesos de modernización. Estos colectivos se caracterizan por congregar fuerzas diversas que se enfrentan a un enemigo común, utilizando los instrumentos de defensa disponibles -entre los que se encuentran la propia legalidad, las manifestaciones públicas o los medios de comunicación. Aquí la fiesta es reemplazada por la crítica y el entusiasmo por la lucha, en una disputa por la definición de la realidad -principalmente con la institucionalidad vigente-, reivindicándose de paso la legítima capacidad del colectivo para determinar bienes dignos de conservación.

En el caso chileno, tal como ocurre en muchos países miembros de la UNESCO, uno de los agentes fundamentales en la construcción de significados patrimoniales es el Estado, cuando no el mercado, en tanto selecciona referencias representativas que permiten consolidar ciertos actores políticos, discursos y modelos de actuación (Guerrero, 2012). Si bien es cierto que en las últimas décadas las organizaciones civiles enfocadas en temas patrimoniales han tomado fuerza, las herramientas de participación institucionales siguen estando orientadas antes a la consulta e información, que a la posibilidad de una incorporación efectiva de la ciudadanía en la co-gestión y evaluación de iniciativas. Un ejemplo paradigmático de estas limitaciones es el proceso de inscripción de la ciudad Valparaíso como Pa- 
trimonio de la Humanidad el año 2003, respecto del cual organizaciones ciudadanas en su momento consideraron que

los contenidos patrimoniales o lo que ha sido considerado el patrimonio formal de la ciudad y los objetivos del mismo, han sido definidos fundamentalmente por actores estatales y por algunos grupos de académicos y expertos convocados por estos para validar sus objetivos. (Guerrero, 2012, p. 13)

Similarmente, en el caso de la puesta en valor del vino pipeño del Valle del Itata, se ha sugerido que los discursos y experiencias de las comunidades implicadas en su producción han sido apropiadas por lógicas instrumentales y hegemónicas externas (Mariángel, 2019).

En línea con esta noción de patrimonio formal, ciertos autores distinguen -desde el patrimonio crítico- los procesos de construcción de un patrimonio oficial y otro no oficial (Marsal, 2012; Högberg, 2016). De acuerdo con esta clasificación, el primero se sostiene en un conjunto de elementos promovidos por la nación y/o Estado para ser reconocidos, aprehendidos y socializados a través de la educación formal, ritos, conmemoraciones e instituciones. El segundo está conformado por todos aquellos elementos que resultan significativos para ciertas comunidades locales en tanto crean identidad y sentido de pertenencia, pero que al no ser reconocidos por el Estado, carecen de protección formal.

Esta noción de patrimonio oficial encuentra similitudes con la de patrimonio 'declarado', utilizada por Guerrero (2005), para referir a procesos de selección, valorización y negociación dirigidos desde los Estados, o movimientos nacionalistas, con el objeto de construir símbolos metonímicos de identidad, excelencia y creatividad de una comunidad imaginada que representen una nación unitaria, integrada y homogénea. Lo 'declarado' aquí es investido a través de la prevalencia de lógicas de poder e intereses de mercado, conformando un patrimonio oficial desplegado a través de una arquitectura ad-hoc. En contraposición se encuentra el patrimonio 'apropiado', que se escenifica en aquellas formas simbólicas que adquieren un valor significativo para comunidades de pequeña escala, ancladas a un territorio que actúa como contexto. Lo patrimonial aquí responde a una necesidad de memoria e identidad con valores comunes, por lo que determinadas prácticas y saberes son vividas al compartirlas, constituyéndose en símbolos de identidad socio territorial.

Malavassi (2017) sugiere categorías similares, aunque vistas bajo una perspectiva distinta. Sostiene que en la elaboración del patrimonio ope- 
ra un proceso de 'objetivación' institucional, en tanto potestad de identificación de manifestaciones u objetos posibles de poner en valor. Pero este siempre se acompaña de un 'anclaje', en tanto forma en que las personas, usuarias o partícipes de lo objetivado lo reinterpretan, produciendo sus propias referencias simbólicas. De ahí el valor ascendente, por ejemplo, de criterios como autenticidad y espíritu de lugar, nociones que incluso actualmente son reivindicadas desde la institucionalidad, como formas de ir consolidando procesos de objetivación, pero que en su puesta en escena dan origen a tensiones y formas no uniformes de puesta en valor.

Siguiendo esta tendencia, ya no es tan fácil que el Estado nación pueda imponer sus valores a través de la objetivación, o pueda instalar un patrimonio oficial o declarado, porque ha de entrar en procesos de interacción con agentes y comunidades diversas para establecer vías de negociación en la elaboración de significados simbólicos comunes y representativos.

En síntesis, la actividad patrimonial se posiciona básicamente como un ejercicio de construcción de relatos compartida, en donde la clave parece ser la relación entre diversas comunidades, pero no solo vecinales o étnicas; también académicas, científicas, de expertos, políticas, u otros grupos de interés sectorial y de sensibilidades que operan en torno al proceso de asignación de valor (Guerrero, 2005; Nordenflych, 2013). Entre estos agentes han de consensuar y buscar perpetuar, aunque sea dentro de un marco de permanente disputa, distintas narrativas que darán cuerpo a lo que llamamos activación patrimonial, dinámica que se ha hecho parte del proceso de construcción de sentido de pertenencia a una comunidad determinada, entendida esta como una idea común aglutinante que da forma a la vinculación con el territorio.

De esta manera, el proceso de activación patrimonial finalmente opera como un proceso interpretativo que incorpora aspectos racionales y funcionales, pero también emocionales, incentivando a que las personas se apropien, re-elaboren y promuevan cualidades simbólicas que refuercen la puesta en común (Homobono, 2008). En última instancia, no hay que olvidar que la acción de los agentes, o comunidades patrimoniales, surge en respuesta a la sensación de riesgo y pérdida (Segalén, 2003; Ariño, 2010). Y si las amenazas son percibidas como un peligro para la propia existencia, frente a ello es que se activan mecanismos de orden simbólico que permiten poner en circulación valoraciones, objetos, testimonios o prácticas que, por defecto, se definen como sensibilidades constantemente 'agredidas' por aquello mismo que define su lucha: el olvido. 


\section{METODOLOGÍA Y TÉCNICAS DE INVESTIGACIÓN UTILIZADAS}

El siguiente artículo indaga en los discursos y acciones que conformaron el proceso de activación patrimonial de la FBOT, a partir de los relatos de quienes participaron en él, con el fin de generar un conocimiento situado, es decir, generado en un tiempo y espacio determinado (Restrepo, 2018).

La investigación tuvo dos momentos: primero, una búsqueda de información en fuentes secundarias, a lo que siguió el desarrollo de entrevistas en profundidad. En la primera etapa se hizo revisión de publicaciones web de páginas institucionales (PLADECO comunal, Proyecto de modificación del borde costero del MOP), material facilitado por actores sociales (Periódico La Trama, archivos SERVIU), prensa escrita digitalizada (Archivos diario El Sur desde el año 1964 al 2000), diversas tesis de pre y posgrado universitarias, así como memorias e informes de instrumentos de planificación. Los criterios utilizados en estas búsquedas fueron temporales y territoriales (barrio Bellavista y sector Borde Costero de Tomé), y permitieron elaborar un 'estado del arte' respecto de acciones de preservación o afectación del patrimonio, así como otras orientadas al desarrollo local en la ciudad. Posteriormente, durante el año 2019, se realizaron 12 entrevistas en profundidad a diferentes agentes del Estado en la región y la comuna, del mundo académico y miembros activos -o que hubiesen sido parte-, de organizaciones sociales relacionadas con el área de estudio ${ }^{1}$.

Por el volumen de información disponible, y la diversidad de fuentes utilizadas, para el análisis se recurrió a su triangulación, procedimiento que permitió contrastar lo relevado (Okuda y Gómez-Restrepo, 2005). El foco estuvo siempre sobre la mirada de los actores sociales, para observar los mecanismos de producción de sentido en la manera como se decían las cosas desde determinados anclajes espaciales, temporales y sociales. $\mathrm{O}$ sea, asumiendo que cada texto, en tanto acción social, ocurre en un marco de comprensión, comunicación e interacción, que a su vez forma parte de estructuras y procesos socioculturales más amplios (Vieytes, 2004). Este proceder permitió otorgar más importancia a los discursos que a la individualidad de cada agente (Baeza, 2002).

\footnotetext{
${ }^{1}$ Los investigadores se han guiado éticamente por las Pautas éticas internacionales para la investigación relacionada con la salud con seres humanos (CIOMS, 2016) y en consecuencia han estimado que el trabajo de campo involucra conocer y manipular datos sensibles de la población objeto de estudio. En ese marco, a los y las entrevistados/as se les garantizó no solo la confidencialidad y anonimato de lo expresado verbalmente, sino también las garantías de protección al uso y manejo de la información entregada.
} 


\section{FÁBRICA BELLAVISTA OVEJA TOMÉ COMO PATRIMONIO}

\subsection{Surgimiento y consolidación de la activación patrimonial}

La Fábrica de Paños Bellavista Oveja Tomé se ubica en la zona centro sur de Chile, Región del Biobío (Fig. 1). Su historia comienza en 1865, bajo el nombre de Fábrica de Paños Bellavista, y fue en su momento la industria textil más importante del país (Saavedra, 2006; Becker et al., 2010; Cartes et al., 2012). Su quiebra -el año 2007- significó un duro golpe no solo para sus trabajadores, sino también para el conjunto de la ciudad de Tomé. Su compra el año 2010 por parte del Grupo Sabat -a través de un leasing del Banco de Chile-albergó por momentos la idea de una pronta reapertura, pero en la práctica el actuar de sus nuevos dueños fue tendiendo hacia el desmantelamiento y transformación del espacio físico de la industria textil ${ }^{2}$.

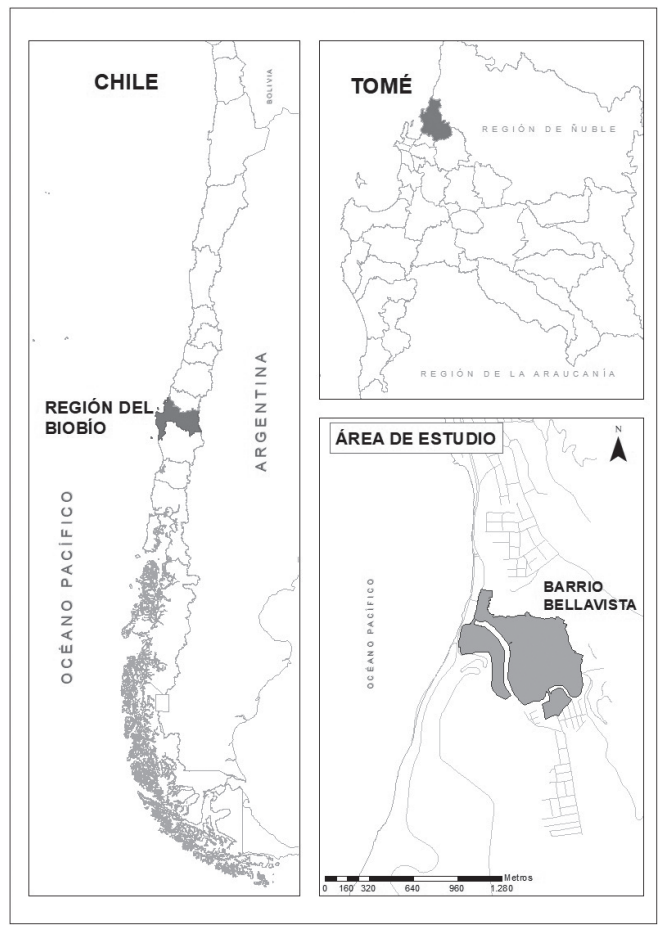

Figura 1. Ubicación de la población Bellavista construida en torno a la Fábrica en la Región del Biobío, en la zona centro sur de Chile. Fuente: Elaboración propia.

\footnotetext{
${ }^{2}$ Actualmente, la Fábrica está en manos de la Sociedad Inmobiliaria Puerto Madero, en la que participan los hermanos Juan José y Juan Carlos Sabat. El segundo, en su calidad de socio y Gerente General, ha sido desde un principio la cara visible de los nuevos propietarios.
} 
En este contexto, su declaratoria como Monumento Histórico en 2017 viene a marcar un punto de inflexión en su historia, por cuanto su definición como espacio fabril debe dar paso a una nueva figura, aún no definida, aunque dependiente del proceso de activación patrimonial que albergó. Pero ¿cuándo se inició este proceso? Para responder esta pregunta hay que retrotraerse a la memoria del Plan Regulador Comunal (PRC) de Tomé de 2008, donde se encuentran las primeras señales sobre la consideración de un valor social asociado al patrimonio en la ciudad. Específicamente, se mencionan zonas de interés patrimonial, definiéndose diversos conjuntos e inmuebles en el barrio Bellavista (excluida la Fábrica) y en el barrio Carlos Mahns como Zonas o Inmuebles de Conservación Histórica (ZCH o ICH) -tomando en consideración el Plan Regulador Metropolitano de Concepción del año 2003 y su énfasis en los "patrimonios existentes". También asociados a esta época se desarrollan los planes de Recuperación del Borde Costero de Tomé (Moraga, 2007), conjunto de iniciativas con las que se alineó el respectivo PLADECO 2008-2012 (Ilustre Municipalidad de Tomé, $\mathrm{s} / \mathrm{f}$ ), para definir como uno de sus lineamientos estratégicos el 'turismo sustentable. Con ello se propiciaba la mejora de infraestructura y equipamiento turístico para la generación de productos y servicios que considerasen el rescate histórico cultural de la industria textil en el conjunto de la comuna ${ }^{3}$.

Aunque para esa época las preocupaciones de los habitantes del barrio Bellavista giraban más bien alrededor de la quiebra de la Fábrica -su posible cierre, los despidos y la cesantía consiguiente-, el proyecto de remodelación de la Plaza de Armas de la ciudad (Fig. 2), encabezado por la Municipalidad de Tomé el año 2009, implicó un llamado de atención para muchos y quedó marcado como hito de inicio de un proceso ciudadano de activación patrimonial.

\footnotetext{
${ }^{3}$ Dado que la Fábrica de Paños Bellavista no fue la única en la ciudad. A ella le siguieron la creación de: la Sociedad Nacional de Paños Tomé (1914), la Fábrica de Paños y Tejidos El Morro (1924) y la Fábrica Italo Americana de Paños, FIAP (1926). (Ver Pérez y Lagos, 2014).
} 




Figura 2. Vista de la Plaza de Armas el año 2006, antes del proyecto de remodelación. Fuente: colección privada H. Basoalto.

... trabajábamos...bueno, en realidad algunos artistas, alguna gente interesada en la historia y muchas gentes común y corriente que se interesó solamente en defender la plaza y ahí hicimos (...) bueno, muchas cosas en realidad... estuvimos en la plaza recolectando firmas, estuvimos tratando de concientizar también, de decir bucha, defendamos lo de nosotros también, por qué va a venir una autoridad a cambiarnos algo que en realidad nosotros usamos como tomecinos... (entrevistado n ${ }^{\circ}$ 10, habitante de barrio Bellavista, realizada 28/9/2019)

En la misma línea,

... ahí es donde yo voy al sentimiento que la gente de aquí de Tomé se involucra en estos temas cuando hay algo sentimental detrás, no con números, ni cosas tan frías (...) el espacio de la plaza era ocupado por gente (...) la pileta la veíamos ahí, jugábamos ahí (...) nuestros hijos jugaban ahí (...) o sea era algo que nosotros teníamos ahí, que lo ocupamos, que lo sentíamos como nuestro... (entrevistado no 10 , habitante de barrio Bellavista, realizada 28/9/2019) 
De esta circunstancia, que aglutina elementos tanto emocionales como racionales, emerge el Consejo Comunal para el Patrimonio de Tomé (CCPT), organización sin fines de lucro creada a instancias de la comunidad tomecina, para "responder a la necesidad de contar con un grupo jurídicamente organizado que diera cumplimiento a los objetivos de defensa, protección y difusión de los valores patrimoniales, tanto materiales como inmateriales, así como culturales, naturales, arquitectónicos y sociales" (Consejo Comunal por el Patrimonio de Tomé, 2014, s.p.). Esta incipiente organización también estuvo estrechamente ligada a la defensa ciudadana de la Fontana de Tritones de la misma plaza, muy deteriorada después del terremoto de 2010, y de la fallida defensa de la Casa Hinrichsen, inmueble ubicado en el centro de Tomé que a pesar de haber sido declarado Inmueble de Conservación Histórica (ICH) en el Plan Regulador Comunal de 2008, fue adquirido por un privado y se comenzó a demoler sin que la Municipalidad interviniera. Esto último constituyó un verdadero hito que marcó un aprendizaje para la comunidad incipientemente organizada: "El caso de la Casa Hinrichsen fue una pérdida que tuvimos, llegamos tarde y fuimos ingenuos en las decisiones políticas que se tomaron porque antepusieron las posiciones técnicas..." (como se citó en Ortega, 2016, p. 192).

No obstante los tropiezos, estos eventos activan una interacción entre la ciudadanía organizada (básicamente el CCPT) y el Municipio, lo que permite trabajar conjuntamente la declaratoria como Monumento Nacional del Deportivo y Cine Bellavista, presentada formalmente por la entidad edilicia y resuelta en 2013 mediante el Decreto no 46 (Consejo de Monumentos Nacionales, 2013). Con posterioridad a ello, se presenta la carpeta para solicitud de declaratoria en la misma categoría de la FBOT, elevada al Consejo de Monumentos Nacionales por parte de la casa edilicia a inicios de 2014. Todo indica que esta última gestión se vio acelerada por la constatación del riesgo que significó advertir que los propietarios de la fábrica empezaran a tramitar la subdivisión de las aproximadamente 6.5 hectáreas de terreno que componen la FBOT en 8 paños, gestión que habría despertado las alarmas en una ciudadanía ya organizada (Fig. 3). 
PLANTA PROPUESTA mos sillos anexos o Cuesk Corocoles - PROYECIO DE SUBDIVISION ESCALA I: 1000

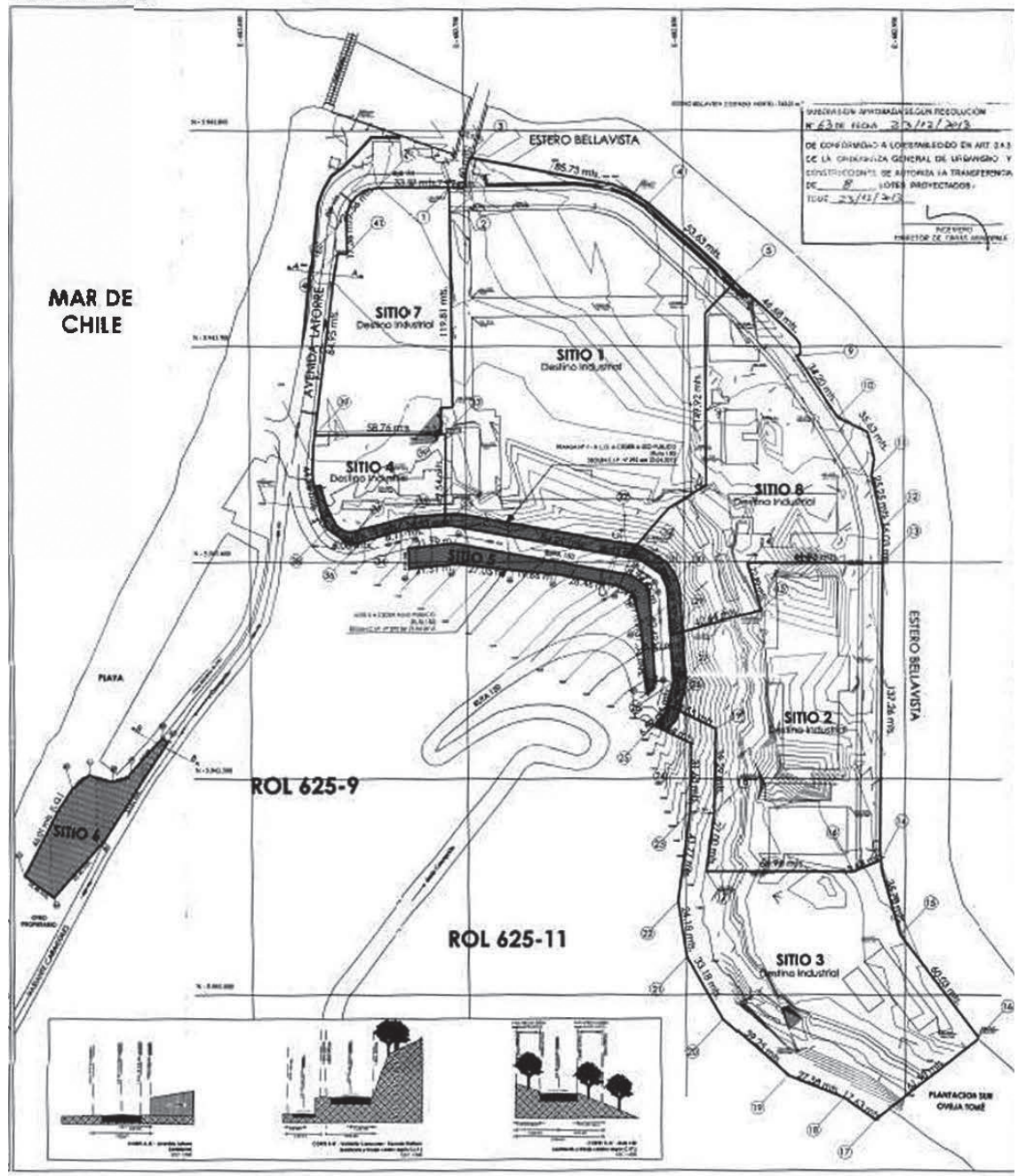

Figura 3. Plano de subdivisión del terreno de la fábrica en 8 paños. Fuente: DOM, Municipalidad de Tomé.

De alguna manera, a través de esta eventualidad, inicialmente negativa, se acaba por involucrar una porción mayor de la comunidad tomecina, demostrándose una preocupación que excede el ámbito exclusivo del interés en torno a la fábrica y se extiende como reivindicación más generalizada en torno a la defensa del patrimonio local. 
... el patrimonio no solamente es lo que se considera de la alta cultura, como una visión bastante tradicional (...) también se puede considerar patrimonio el espacio habitado, el espacio utilizado. Y después, más adelante, se empezó a considerar también, se tomó en cuenta el patrimonio inmaterial, las formas de vida, las formas de habitar... (entrevistado $n^{\circ} 1$, habitante de Tomé, realizada 30/4/2019)

De alguna manera, la tramitación de subdivisión acaba por fortalecer un discurso patrimonial que reivindica el rescate de identidades asumidas como históricas, aunque amenazadas por el olvido. Es una narrativa asumida por agentes ciudadanos que encuentran en la conexión emocional con determinados espacios de experiencia colectiva un factor vinculante, que les permite compartir significados y vivencias comunes. $Y$ en este contexto, la fábrica se erige como un símbolo que aglutina a una comunidad en torno a experiencias comunes.

... la fábrica viene siendo como la mamá de Bellavista, yo siento que de ahí, de ese útero, nació la población, nació todo pu (...) sin la fábrica no hubiera sido Bellavista, tal vez Tomé... (entrevistada n5, habitante del barrio Bellavista, realizada 24/6/2019)

\subsection{Desde el 'anclaje' a la 'objetivacion' del patrimonio}

Pero la sensación de amenaza, además de ser un pilar en la consolidación de un discurso de defensa, preservación y difusión de lo patrimonial por parte de las organizaciones ciudadanas, también permea el vínculo que estas mantienen con la institucionalidad. Por ejemplo, se observa con recelo el obrar de la Municipalidad, entendiéndose como reactivo -más que proactivo- en la defensa de los intereses patrimoniales de la comunidad; pero también ambiguo, por su vínculo con los privados, situación que se intensifica cuando en enero de 2016 los propietarios del inmueble ingresaron a la Municipalidad una solicitud de cambio de uso de suelo, de industrial a residencial, comercio y servicios, proponiendo mantener las fachadas principales de la Fábrica y su Torre del Reloj (Fig. 4). La solicitud incluía también un proyecto para la construcción de departamentos y un strip center, junto con la intención de dejar una pequeña parte para la producción industrial. El argumento de fondo era que, de ser declarada MH la totalidad de la superficie de la fábrica, esta tendría que cerrarse, puesto que "si no recibo ingresos, no puedo gastar plata en su mantención" (Sabat, J., 
como se citó en Placencia, 2018, s.p.). Este argumento nunca fue objetado o interpelado por las autoridades municipales.

Adicionalmente, se observa en esta etapa el ingreso de expertos académicos en el proceso de construcción del discurso patrimonial, lo que se traduce en la realización de talleres participativos por parte del Centro de Desarrollo Urbano Sustentable de la Universidad de Concepción (CEDEUS) en 2013 y la implementación en Bellavista del programa "Quiero mi Barrio", del Ministerio de Vivienda y Urbanismo, el año 2015. Con este arribo de técnicos y académicos, que entran directamente a apoyar el trabajo de la comunidad, el proceso de activación se abre más allá de las fronteras de Tomé, hacia los espacios y lenguajes por los que los académicos y profesionales externos circulaban:

Yo creo que al principio éramos más gente que queríamos el patrimonio, pero a medida que se fueron engordando las filas del Consejo (CCPT) llegaron arquitectos, profesores, restauradores, que le daban otra sustancia, no solamente hablaban desde el romanticismo, sino que había un sustento más técnico. (como se citó en Ortega 2016, p. 189)

Estos elementos conllevan el surgimiento de un discurso más crítico y receloso de la institucionalidad por parte de las organizaciones sociales. Tal cambio se refleja, por ejemplo, en la conformación de la Mesa Ciudadana por el Patrimonio de Tomé (MCPPT), en 2016, que reúne a más de una docena de organizaciones sociales tomecinas, enfocada en "ampliar la participación ciudadana y presionar por distintas vías a las autoridades, junto con convocar a equipos de profesionales para afrontar un proceso de rescate que no es fácil ante el deficiente marco institucional" (Consejo por el Patrimonio de Tomé, 2016).

De esta manera, se observa que otra vez la organización y movilización emergen desde la urgencia.

... nos llegó el dato como Consejo del Patrimonio de que se iba a demoler la fábrica y que se iban a construir edificios de departamentos..., eso era inminente, porque ya se había entregado en la Municipalidad toda la idea para sacar los permisos, entonces... cuando supimos eso era actuar rápido sí o sí o la fábrica se demolía... (entrevistado $\mathrm{n}^{\circ} 10$, habitante de barrio Bellavista, realizada 28/9/2019) 


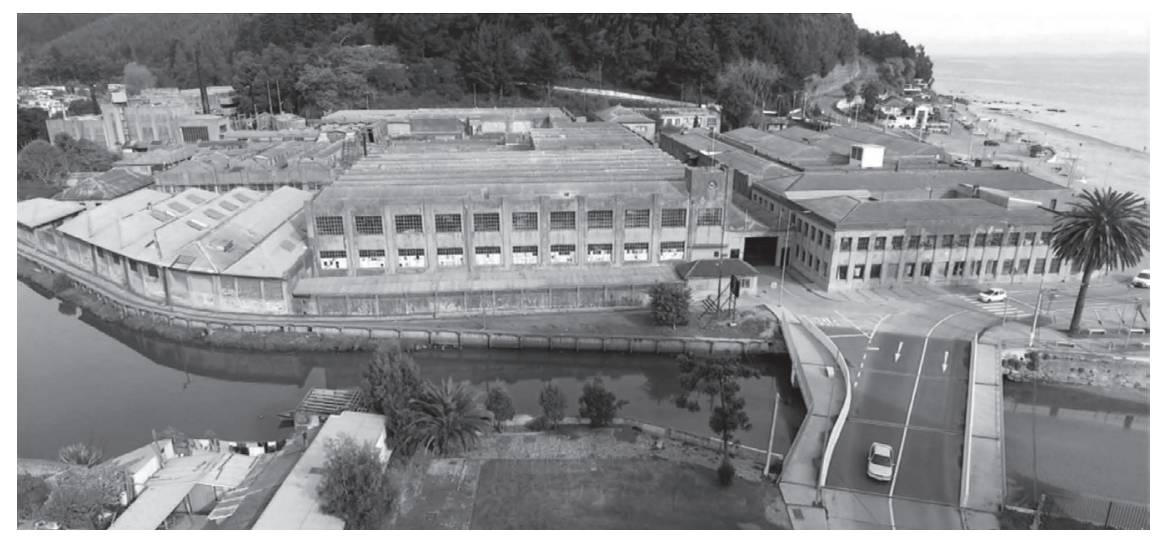

Figura 4. Vista aérea de la fábrica de Paños Bellavista Oveja Tomé. Fuente: Archivos del Consejo de Monumentos Nacionales.

Bajo este nuevo prisma, ahora no solo se recolectaron firmas y enviaron cartas, sino que también se utilizaron nuevas redes y, por ejemplo, se solicitó una visita formal de personeros del CMN, con el fin de acelerar la tramitación.

... el proceso partió de la solicitud que realizaron las comunidades (...) en las gestiones, tanto políticas como técnicas, el Consejo de Monumentos sintió el apoyo de la comunidad, que se entiende que sin comunidad no hay patrimonio, entonces por eso mismo tomó tanta relevancia esta declaratoria, porque salió desde la gente... (entrevistado no 9 , ex miembro del CMN Biobío. Entrevista realizada 12/9/2019)

El 13 de abril del mismo año, el CMN falla favorablemente la declaración de la totalidad de la FBOT como Monumento Nacional, fallo que no fue del todo bien recibido por la Municipalidad, no obstante haber sido la institución que elevó la solicitud de declaratoria. Fiel a su postura ambigua, en el acta de la sesión del CMN, queda claro que el interés de la casa edilicia era "que exista flexibilidad en la protección, que se generen las condiciones con los empresarios y que se evalúe la protección sólo de los edificios del acceso, no de todo el predio" (Consejo de Monumentos Nacionales, 2016). Por parte de los propietarios, la noticia fue muy mal recibida. En nombre de Bellavista Oveja Tomé, el 1 de julio se interpone un requerimiento de 
inaplicabilidad de la declaratoria en trámite, cuestionando la constitucionalidad del artículo 12 de la ley 17.288 de Monumentos Nacionales. Por último, para las organizaciones ciudadanas, el fallo fue considerado histórico y simbólico: significó un triunfo de los intereses colectivos por sobre los particulares. Lo ganado, más que un espacio, era una memoria colectiva inserta en el alma cultural de los tomecinos, reivindicada por medio de la declaratoria. Al decir de un vecino, “... todos teníamos algún vínculo con alguien que había trabajado o trabajó en las fábricas textiles...era algo común que teníamos y buscamos eso... (entrevistado ${ }^{\circ} 10$, habitante de barrio Bellavista, realizada 28/9/2019).

Finalmente, la ratificación del fallo vino el 7 de noviembre de 2017. Y a pesar de lo señalado por la institución en el Acta del CMN de 2016, desde el municipio se hace ver que "Estamos muy satisfechos como municipio por esta declaratoria. Es una noticia que en Tomé esperábamos desde 2014 (...) y hoy podemos decir que este símbolo de la industria textil es patrimonio de todas y todos" (Rivas, I., como se citó en Municipalidad de Tomé, 2016, párr. 2). En contraste con la ambivalencia estatal, los administradores de la fábrica mantienen inalterable el discurso de oposición, "simplemente todo se está cumpliendo. Este edificio será un nido de ratones y palomas. No aportará nada al pueblo de Tomé. Declararlo Monumento Nacional fue una pésima idea" (Bartoli, como se citó en Placencia, 2018, párr. 11).

Las organizaciones ciudadanas, después de celebrar un triunfo sentido como propio, comenzaron a ver cómo enfrentar el nuevo escenario, en alguna medida sorpresivo. Se crea, en 2018, la Corporación La Fábri$\mathrm{ca}$, estructura con personalidad jurírica propia que busca ser parte de la institucionalidad que defina el nuevo uso y administración del edificio. A partir de aquel momento, será esa la instancia de interlocución ciudadana en relación a la fábrica, tanto con las autoridades políticas, como con los propietarios y el mundo académico. Y desde este espacio, las organizaciones sociales interpelarán de forma permanente para que el Estado adquiera la Fábrica y así, de forma comunitaria, se rearme y defienda un lugar que encarna la historia e identidad como una posibilidad de proyecto de desarrollo productivo y cultural.

\section{DISCUSIÓN}

En los procesos contemporáneos de construcción social del patrimonio, verdaderos campos de disputas de selección y valoración de símbolos, cobran gran importancia las dinámicas de negociación entre pluralidad de 
actores, resultando siempre definiciones que actúan como contratos implícitos y siempre provisionales. De ahí la importancia de los agentes patrimoniales que logran conformarse como interlocutores, interactúan y otorgan legitimidad al proceso.

En Tomé este se activa cuando distintas comunidades locales se agrupan a propósito de la defensa de la Plaza de Armas (ciudadanía organizada v/s Municipalidad). Continúa luego con la defensa de la casa Hinrichsen (se incorporan otras instituciones del Estado a la interacción) y encuentra su punto más alto en el proceso para la declaratoria como $\mathrm{MH}$ de la fábrica Bellavista Oveja Tomé (sumándose los propietarios y el mundo académico).

En un principio el Estado, que ve el turismo como un eje de desarrollo económico para la comuna, visualiza el patrimonio como un recurso para potenciarlo. Pero las organizaciones ciudadanas incorporan una mirada más compleja. Para estas, la preservación del patrimonio se define en pos de la defensa de valores experienciales que construyen memoria y sentido de pertenencia, escenario en el cual el turismo es únicamente un mecanismo de difusión de elementos simbólicos que configuran ese legado.

Tal como lo señalan los estudios del patrimonio, este recorrido emerge en reacción a la percepción de amenaza (Segalén, 2003; Homobono, 2008; Ariño, 2010). En este caso, sentida por los dos agentes patrimoniales que inicialmente interactuaron, ya que tanto el municipio como las organizaciones ciudadanas mostraron preocupación por la idea de pérdida, aunque asumiendo perspectivas diferentes. La casa edilicia visualizaba la pérdida a partir del desperdicio de una oportunidad de desarrollo turístico. En tanto, la aprehensión ciudadana se construyó a partir de la evaluación de un actuar del municipio evaluado como reactivo y con una mirada deficiente de las nociones de protección y conservación. Por ello, cuando la atención comienza a centrarse en la fábrica Bellavista, las agrupaciones asumen que la amenaza de pérdida podía acabar en su destrucción y olvido.

Lo interesante es que en este escenario, tal y como señala Ariño (2010), las organizaciones ciudadanas implementaron estrategias de presión que incluyeron no solo acciones reactivas orientadas a frenar decisiones ya tomadas -tales como las recolecciones de firmas, cartas o manifestaciones sociales-, sino también demandas de participación real y concreta en la construcción del discurso oficial sobre lo propio, entendiendo que contaban con los argumentos y vivencias que sustentaban aquella exigencia. Esta demanda logró la reelaboración de los planteamientos iniciales dispuestos por los representantes estatales, quienes tuvieron que complementar los 
aspectos más técnicos con aquellos que rescataban la condición subjetivaexperiencial que rodeaba la fábrica. Este giro simbólico emerge como una característica de los procesos patrimoniales contemporáneos ligados a la construcción de identidades colectivas, en los cuales el discurso de las organizaciones ciudadanas si bien se distancia del oficial, no lo invalida, sino que lo complementa.

En este contexto de relaciones tensionadas, pero complementarias, el discurso de las organizaciones ciudadanas, reforzado por un creciente apoyo ciudadano, va conformando un marco dentro del cual comienzan a moverse -a veces con una explícita incomodidad- no solo los agentes del Estado, sino también los propietarios, quienes con la aparición de la comunidad ciudadana en la escena ven sus planes de desarrollo inmobiliario enfrentados a una amenaza imprevista.

Adicionalmente, esta reelaboración de contenidos de lo patrimonial que incorpora las vivencias, la memoria y la identidad local, permite a las organizaciones ciudadanas ocupar un lugar desde el cual interpelar públicamente el actuar del Estado y de los propietarios, ganándose con ello un espacio mediático que refuerza la validez del trasfondo emocional del discurso. Posiblemente, esto explica que los hitos burocráticos por los que pasó la declaratoria de la fábrica fuesen básicamente interpretados por unos y otros como eventos reivindicativos que reconstruían la historia de la ciudad, pero desde la perspectiva de sus habitantes. Fueron instancias construidas desde la emocionalidad y, a partir de sus resultados, leídas como triunfos ciudadanos. Frente a esta evolución del proceso, el municipio -con o sin convicción- no tuvo más opción que sumarse; mientras los propietarios optaron por seguir inalterables en cuestionar su legalidad buscando anular agitaciones y exaltaciones para seguir una línea estrictamente judicial.

\section{CONCLUSIONES}

Desde una perspectiva global, el caso de la FBOT reafirma la validez de las tres grandes categorías de agentes sociales identificadas en el marco teórico, el mercado, el Estado y las organizaciones ciudadanas, como los grandes grupos que interactúan, aunque con agendas disímiles, en procesos de puesta en valor.

A partir de estas diferenciaciones un aspecto interesante que surge es la condición flexible y adaptable, tanto de las estrategias como de los discursos, de aquellos agentes patrimoniales que deciden entrar en la disputa de la 
elaboración de los símbolos sin desdeñar su cara emocional: agrupaciones ciudadanas y el aparato estatal. Resalta en este campo la difícil ecuación que experimentan en particular los agentes estatales para conciliar los objetivos de representatividad política de las voces populares con los objetivos de desarrollo económico neoliberal, estos últimos en alianza con el mercado.

En contraste, la posición fija e intransable de los propietarios puede ser interpretada de diversas maneras. Si bien es cierto que por el momento el triunfo parece haber quedado del lado de las organizaciones ciudadanas, lo cierto es que la propiedad del bien sigue asegurando para los propietarios el poder de bloquear cualquier intento futuro de gestión del mismo. Esto podría hacer pensar que la estrategia de este grupo no sería otra que apostar por el desgaste natural del edificio y de los movimientos ciudadanos que lo reclaman, cuestión que finalmente pone en evidencia la fragilidad de la normativa oficial en torno a lo patrimonial en el país.

En este contexto, emerge en el análisis un cuarto grupo -no destacado en los referentes teóricos- que podría parecer irrelevante, en tanto su paso es aparentemente el menos comprometido con una causa o agenda propia, pero cuyo impacto se observa en la manera en que se despliega el proceso. Es el grupo de 'la academia' que, a partir de su conocimiento 'técnico', surge como facilitador de dispositivos discursivos que permiten validar ante la institucionalidad la agenda patrimonial de las organizaciones sociales, definida inicialmente como emocional por los mismos/as actores. Se puede decir que traducen a un lenguaje 'objetivo' u objetivado (Malavassi, 2017), admisible en el ámbito de las instituciones, el discurso emotivo de las organizaciones ciudadanas, a la vez que aportan a estas mismas organizaciones los argumentos técnicos y teóricos que les permiten complementar y reforzar sus posiciones, con el fin de negociar la construcción de símbolos en mejores condiciones.

Dicho esto, hay que señalar que la aparente neutralidad de este cuarto grupo no es tal. El caso de estudio revela cómo el discurso de la academia introdujo sus propias contradicciones en el proceso, tensionando la relación de las organizaciones internamente, y también con la administración pública y los intereses privados.

Finalmente, el caso analizado permite distinguir dos procesos. Uno inicial de 'objetivación' patrimonial en el cual el Estado -en acuerdo con la academia y el mercado- opera en el sentido que señala Malavassi, seleccionando ciertos conjuntos arquitectónicos y definiendo una narrativa patrimonial funcional a una agenda de desarrollo turístico-patrimonial. Pero un segundo proceso opera en un sentido inverso, con las organizaciones socia- 
les 'anclando' el bien excluido, definiéndolo como bien primigenio (i.e. 'la mamá de Bellavista') y, a través de la resistencia y el activismo, logrando su ascenso al estatus de patrimonio 'oficial' u 'objetivacion' institucional.

Este resultado contradice a quienes ponen en duda el impacto democratizador de la tendencia actual en la activación patrimonial en Chile. No obstante, sigue evidenciándose un problema en las lógicas de construcción de la interrelación entre los distintos agentes que participan del proceso, lo que genera dificultades principalmente a la hora de proyectar la gestión del bien patrimonial, el cual aparece como desligado del proceso de activación patrimonial y, por lo tanto, de los agentes patrimoniales que le dieron vida.

\section{REFERENCIAS}

Ariño, A. (2010). La patrimonialización de la cultura y sus paradojas postmodernas. En D. Porporato (ed.). Nuove pratiche di comunità. I patrimoni culturali etnantropologici fra tradizione e complesità sociale (pp. 15-32). Omega Edizioni. https://www.academia.edu/1198690/La_patrimonializacio_n_de_ la_cultura_y_sus_paradojas_postmodernas

Baeza, M.A. (2002). De las metodologías cualitativas en investigación social: Diseño y uso de instrumentos en la producción de sentidos. Concepción: Editorial Universidad de Concepción.

Becker, E., Pérez, S., Saavedra, M. y Saldías, E. (2010). Bellavista. Memoria oral de un pueblo industrial. Concepción: Publicación Fondart, Gobierno de Chile.

Cartes, A., López, L. y Luppi, R. (2012). Bellavista Oveja Tomé. Una fábrica en el tiempo. Concepción: Ediciones Universidad de San Sebastián.

Consejo Comunal para el Patrimonio de Tomé. (3 de marzo 2016). Mesa Ciudadana por el Patrimonio de Tomé defiende recinto de la Fábrica textil de Bellavista. Blog de Consejo Comunal Para el Patrimonio-Tomé. http:// consejopatrimoniotome.blogspot.com/2016/03/mesa-ciudadana-por-elpatrimonio-de.html

Consejo Comunal para el Patrimonio de Tomé. (8 de junio 2014). Blog Consejo Comunal para el Patrimonio de Tomé. http://patrimoniotome.blogspot. com/2014/06/consejocomunal-para-el-patrimonio-tome.html

Consejo de Monumentos Nacionales. (23 de enero 2013). Decreto No 46. Declara Monumento Nacional en la categoría de Monumento Histórico al Deportivo y Cine Bellavista - Tomé. Ubicado en la comuna de Tomé, provincia de Concepción, región del Biobío. https://www.monumentos.gob.cl/servicios/decretos/46_2013

Consejo de Monumentos Nacionales. (13 abril 2016). Acta Sesión Ordinaria del Consejo de Monumentos Nacionales Miércoles 13 abril del 2016. https:// www.monumentos.gob.cl/servicios/actas/acta-sesion-cmn-13-abril-2016 
Consejo de Organizaciones Internacionales de las Ciencias Médicas (CIOMS) y Organización Mundial de la Salud (OMS). (2016). Pautas éticas internacionales para la investigación relacionada con la salud con seres humanos. Ginebra: Consejo de Organizaciones Internacionales de las Ciencias Médicas.

Coronil, F. (2000). Naturaleza del poscolonialismo: del eurocentrismo al globocentrismo. En E. Lander (ed.). La colonialidad del saber: eurocentrismo y ciencias sociales. Perspectivas latinoamericanas (pp. 87-112). Buenos Aires: CLACSO. http://bibliotecavirtual.clacso.org.ar/clacso/sursur/20100708034410/lander.pdf

Guerrero, R. (2005). Identidades territoriales y patrimonio cultural: la apropiación del patrimonio mundial en los espacios urbanos locales. Revista F@ro, 2. http://web.upla.cl/revistafaro/n2/02_guerrero.htm

Guerrero, R. (2012). Patrimonio mundial, territorio y construcción de ciudadanía. Construcción y apropiación social del patrimonio cultural de la ciudad de Valparaíso-Chile. Scripta Nova (XVI). http://www.ub.edu/geocrit/ sn/sn-388.htm

Harvey, D. (2010). Heritage past and heritage presents: temporality, meaning and scope of heritage studies. International journal of heritage studies (7)4, 319-338. http://dx.doi.org/10.1080/13581650120105534

Hernández, J. y Moyano, A. (2007). Patrimonio cultural, movimientos sociales y construcción de la identidad en Andalucía. Andalucía: Centro de Estudios Andaluces. http://researchgate.net/publication/238084383_patrimonio_cultural_movimientos_sociales_y_construcción_de_la_identidad_en_Andalucía

Högberg, A. (2016). Rodney Harrison: Heritage. Critical Approaches. [Review of the book Heritage: Critical Approaches, by Rodney Harrison, 2013]. Norwegian Archaeological Review. ISBN: 978-0-415-59197-3. Doi http:// dx.doi.org/10.1080/00293652.2015.1126632

Homobono, J. (2008) Del patrimonio cultural al industrial: una mirada socioantropológica. En X. Pereiro, S. Prado y H. Takenaca (eds.). Patrimonios culturales: educación e interpretación. Cruzando límites y produciendo alternativas (pp. 57-74). San Sebastián: Donostia. http://www.euskomedia.org/ PDFAnlt/antropologia/11/12/12057074.pdf

Ilustre Municipalidad de Tomé. (s.f.). PLADECO 2008-2012. http://transparencia.tome.cl/53/Pladeco_2008.pdf

Ilustre Municipalidad de Tomé. (13 de abril 2016). Alcaldesa Ivonne Rivas: "la declaración de la Fábrica Bellavista como Monumento es un hecho histórico para Tomé". https://www.tome.cl/noticias/alcaldesa-ivonne-rivasla-declaracion-de-la-fabrica-bellavista-como-monumento-es-un-hechohistorico-para-tome-

Jiménez-Esquinas, G. y Quintero V. (2017). Participación en patrimonio: utopías, opacidades y cosméticos. En T. Vicente, M. J. García y T. Vizcaíno 
(eds.). Actas XIV Congreso de Antropología: Antropologías en transformación: sentidos, compromisos y utopías. http://congresoantropologiavalencia. com/wp-content/uploads/2017/09/XIV-Congreso-Antropologia-PREPRINT.pdf

Jiménez-Esquinas, G. y Sánchez-Carretero, C. (2016). Relaciones entre actores patrimoniales: gobernanza patrimonial, modelos neoliberales y procesos participativos. Revista PH90 Perspectivas 90, 190-197. www.iaph.es/revista$\mathrm{ph} /$ index.php/revistaph/article/view/3827

Maillard, C. (2012). Construcción social del patrimonio. En D. Marsal (ed.). Hecho en Chile. Reflexiones en torno al patrimonio cultural (pp. 15-33). Santiago: Consejo Nacional de la Cultura y las Artes.

Malavassi, R. (2017). El patrimonio como construcción social. Una propuesta para el estudio del patrimonio arquitectónico y urbano desde las representaciones sociales. Diálogos, Revista Electrónica de Historia (18)1, 253-266. http://www.redalyc.org/articulo.oa?id=43952199009

Mariángel, P. (2019). Activación patrimonial y memoria. Alternativas para el reconocimiento del paisaje del vino pipeño como patrimonio subalterno en el Valle del Itata. Sustentabilidad(es) (10)19, 3-30. http://www.sustentabilidades.usach.cl/sites/sustentable/files/paginas/1._paula_mariangel_chavarria.pdf

Marsal, D. (2012). De lo íntimo a la oficialidad: la construcción del patrimonio desde las personas. En Hecho en Chile. Reflexiones en torno al patrimonio cultural (pp. 115-145). Santiago: Consejo Nacional de la Cultura y las Artes.

Moraga, M. (2007) Recuperación del borde costero, la transformación de una ciudad. Tomé. Urbano 10(16), 98-106. http://revistas.ubiobio.cl/index.php/ RU/article/view/381/344

Nordenflycht, J. (2013). El patrimonio es poder. Revista PAT, 56, 38-43. https:// www.patrimoniocultural.gob.cl/614/articles-7011_archivo_01.pdf

Okuda, M. y Gómez-Restrepo, C. (2005). Métodos en investigación cualitativa: triangulación. Revista Colombiana de Psiquiatría XXXIV(1), 118-124. Disponible en https://www.redalyc.org/pdf/806/80628403009.pdf

Ortega, G. (2016). Patrimonio cultural y comunidad. Directrices a partir de la experiencia de la gestión tomecina (Tesis para optar al grado de Magíster en Arte y Patrimonio). Concepción: Universidad de Concepción. http://repositorio.udec.cl/jspui/handle/11594/2038

Pérez, L. y Lagos, K. (2014). La formación y evolución urbana del barrio Bellavista, Tomé. En J. Inzulza y L. Pérez (eds.). Teoría y práctica del diseño urbano para la reflexión de la ciudad contemporánea (pp. 205-217). Santiago: Universidad de Chile y Universidad de Concepción. ISBN 978-956-190846-8.

Placencia, F. (2018, 4 de agosto). Bellavista Oveja Tomé descarta cierre apostando a exportar y crear proyectos. Diario de Concepción. https://www.diarioconcepcion.cl/economia-y-negocios/2018/08/04/bellavista-oveja-tomedescarta-cierre-apostando-a-exportar-y-crear-proyectos.html 
Quintero, V. y Sánchez, C. (2017). Los verbos de la participación social y sus conjugaciones: contradicciones de un patrimonio "democratizador". Revista andaluza de Antropología, 12, 48-69. https://institucional.us.es/revistas/ RAA/12/victoria_quintero_et.pdf

Radio Aguamarina FM de Tomé. (4 junio del 2018). Ante gestiones de Luksic en el TC: organizaciones ciudadanas piden al Estado compra de la Fábrica de Bellavista-Tomé. https://www.facebook.com/radioaguamarina/ posts/10156384802200419/

Restrepo, E. (2018). Etnografía: alcances, técnicas y éticas. Lima: Editorial Universidad Nacional Mayor de San Marcos.

Saavedra, R. (2006). Visión histórica y geográfica de Tomé-Chile. Concepción: Ediciones Perpelén. http://www.memoriachilena.gob.cl/602/w3-article-62479. html

Salgado, M. (2008). El patrimonio cultural como narrativa totalizadora y técnica de gubernamentalidad. Centro-H, 1, 13-25.http://www.redalyc.org/ articulo.oa? $\mathrm{id}=115112534002$

Santamarina, B. (2013). Los mapas geopolíticos de la Unesco: entre la distinción y la diferencia están las asimetrías. El éxito (exótico) del patrimonio inmaterial. Revista de Antropología Social, 22, 263-286. https://revistas. ucm.es/index.php/RASO/article/view/43191

Segalén, M. 2003. Cuestiones de identidad y alteridad. La experiencia francesa del patrimonio. En J. González (ed). Patrimonio y pluralidad. Nuevas direcciones en antropología patrimonial (pp. 41-62). Granada: Diputación de Granada.

Vieytes, R. (2004). Metodología de la investigación en organizaciones, mercado y sociedad: epistemología y técnicas. Buenos Aires: Editorial de las Ciencias. 